\title{
Understanding mindfulness outcomes: a moderated mediation analysis of high-performance work systems
}

Sumi Jha (i) ${ }^{1 \times}$

The purpose of the study was to explain the possible outcomes of mindfulness. The research studied the relationship between mindfulness and employee voice behaviour, affective commitment, job satisfaction, and burnout. The research added one contextual variable, highperformance work system, as a moderator. The sample of the study was faculty members of higher education (management) schools. The sample size was 1092 faculty members. Moderated mediation analysis was used to analyse the data and understand the positive as well as the negative relationship of high-performance work system. Findings indicated the significant positive relationship of mindfulness with employee voice behaviour, affective commitment, and job satisfaction. The research found a negative relationship between mindfulness and burnout. The moderated mediation analysis revealed the significant interaction effect of high-performance work system and mindfulness on consequence variables. To conclude the author found that the mindfulness practice is important for faculty members of higher education. Further the research concluded that mindfulness may enhance employee voice behaviour, which in turn increases satisfaction and commitment and reduces burnout. Such relationship is possible under high performance work system context.

\footnotetext{
${ }^{1}$ National Institute of Industrial Engineering, NITIE, Mumbai, India. ${ }^{凶}$ email: sumi@nitie.ac.in
} 


\section{Introduction}

$\mathrm{n}$ the past few decades, the topic of mindfulness has become several researchers' choice of exploration (Langer, 1989; Shapiro et al., 2006; Brown and Ryan, 2003; Wielgosz et al., 2018; Dahlgaard et al., 2019; Atkinson and Wade, 2019). Atkinson and Wade (2019) noted that mindfulness has been studied from various perspectives like; spiritual, religious, first person and third person. It has also been studied under various disciplines like; psychology, health science and neuroscience (Brown and Ryan, 2003; Dahlgaard et al., 2019). However, despite its rising popularity, empirical research pertaining to mindfulness is scarce (Andrews et al., 2014; Dane and Brummel, 2014; Glomb et al., 2011; Hülsheger et al., 2013). Further, there is limited research in mindfulness in the field of management studies, especially considering the business management faculty in higher education (Bennett et al., 2018). Schwind et al. (2017) and Berila (2015) advocated the need to study mindfulness among teachers because of the immediate impact it has on their students and ultimately on the society.

The choice of higher education is based on the premise that the higher education system is experiencing dramatic changes (Knight, 2015; Darvas, 2018), with the nature (quality and qualification) and enrolment size of students becoming demanding. Langer (1998) defined mindfulness after studying it in the higher education context, with the help of three elements; "continuous creation of new categories, openness to new information and an implicit awareness of more than one perspective" (Bush, 2011, p. 188). Further, Langer (1998) and Siegel (2007) state that mindfulness embodies 'flexible thinking' keeping 'present orientation.' Therefore, as explained by O'Reilly (1998), mindfulness in teaching may be referred to as "being aware, being there, being present, listening and developing inner life by your very attention to the moment" (Bush, 2011, p. 188).

In the context of higher education, mindfulness practice has been reported by Collard et al. (2008), Ramler et al. (2016) and de Bruin et al. (2015). These studies primarily dealt with students' ability to cope with stress and anxiety, some studies were on maintaining emotional balance and worklife over load leading to burnout (Michel et al., 2014; Glomb et al., 2011). The present research extends these findings and studies the effect of mindfulness on burnout on teachers of higher education. Takeuchi et al. (2009) suggested to study the attitudinal consequence variables (like involvement, commitment and satisfaction) to understand workplace mindfulness, therefore, the current research considered faculty job satisfaction (FJS) and affective commitment (AC) as consequence variables. Tuckey et al. (2018) studied the importance of aligned HR practices to enhance the effect of mindfulness. Studies indicated the importance of system intervention and positive personality traits on individual and organizational outcomes (Eby et al., 2019). HRM interventions have been found to facilitate individual's personality in achieving positive outcomes (Jiang et al., 2012; Miao and Cao, 2019). System of complementary and aligned HR practices may help in strengthening the mindfulness and outcome variable relationship. There are studies which hence, a bundle of HR practices termed as high performance work system (HPWS) (Miao and Cao, 2019) is considered as moderating variable for the present study.

The paper aims to fill the gap in understanding the impact of mindfulness in the higher education system. It attempts to study its effect on positive organizational behaviour variables like employee voice behaviour (EVB), and positive attitudinal variables like job satisfaction and AC. Further, the presence of HPWS as a moderator may enhance a powerful effect of mindfulness on employee voice behaviour, FJS and AC. It may result in less burnout among individuals.

\section{Mindfulness}

Bishop et al. (2004) defined mindfulness as being aware, curious, non-judgmental and open to the current situation. Gunaratna (2002) suggested that mindfulness is about accepting and experiencing the present situation as reality. Martin (1997) proposed that mindfulness is a psychological state where an individual experiences a sense of detachment and freedom by focusing on the current purpose, while remaining non-biased and nonjudgmental. Mindfulness has also been studied as a technique to create a sense of purpose and understand the present goal. It creates self-awareness and confidence among professionals (Ritchie and Bryant, 2012). Researchers have advocated mindfulness to be helpful as it promotes the practioner to maintain stable focus on the current purpose (Michel et al., 2014; Saavedra et al., 2010; Cheung, 2018). The focus on purpose may reduce distraction. Sternberg (2000) proposed mindfulness as individual's cognitive style, which means openness to novelty, alertness to distinction, sensitivity to different contexts, awareness of multiple perspectives and orientation in the present. Langer (1989, 1998) found that organizations' approach to gathering information, perception of the environment and the ability to change as the current situation demands constitutes mindfulness. Andrews et al. (2014), Dane and Brummel (2014), Glomb et al. (2011), and Hülsheger et al. (2013) advocated that despite the research potential of mindfulness in various discipline of psychology, there is limited research reported in the social science area. Mindfulness is studied from trait as well as state perspective (Medvedev et al., 2017). The trait form of mindfulness is a permanent ability of individuals to acknowledge what they are thinking and feeling, accept them without any judgement and stay focused in the present. The state form of mindfulness refers to a temporary change in the state of brain, followed by change in the day to day activities. Research also suggest that recurrent activities of state mindfulness will improve the chances of developing trait mindfulness (Kiken et al., 2015; Hölzel et al., 2011). In the present research the trait form of mindfulness is studied with self-report measure of CAMS (Feldman et al., 2007). The trait form of mindfulness helps in understanding participants inherent nature (Kiken et al., 2015). If an individual is mindful, he or she will have a definite pattern of behaviour. Ramler et al. (2016) mentioned that faculty members are identified as someone who shapes students behaviour. Hence, faculty with mindfulness trait may understand students from present context and respond them without any biases. Therefore, trait mindfulness has been considered for the study.

\section{Mindfulness and FJS}

Mesmer-Magnus et al. (2017) found that mindfulness as a trait helps in improving various work-related outcomes. Job satisfaction has been termed as a positive, favourable experience one has towards work/task performed by an employee (Alonderiene and Majauskaite, 2016; Locke, 1969). The positive job attitude and job satisfaction indicate an honest feeling of an employee towards his work (Krueger et al., 2017; Trivellas and Santouridis, 2016). Judge et al. (2001) proposed that employees' capability to focus and pay attention to the present helps in superior performance and satisfaction. Employees having mindfulness will feel contended in the present job (Andrews et al., 2014), leading to a positive evaluation of one's job, resulting in job satisfaction. For faculty members, job satisfaction is real-time (Antony and Valadez, 2002). After each classroom session, the faculty is aware about the delivery in the class. Therefore, mindfulness that focuses more on the current situation and purpose may lead to higher FJS (Andrews et al., 2014; Antony and Valadez, 2002). 


\section{H1 Mindfulness is positively related to faculty job satisfaction}

\section{Mindfulness and burnout}

Burnout is a result of a series of undesirable activities leading to stressful coping by an individual (Maslach et al., 2001). Maslach et al. (1996) explained burnout from a three-dimensional perspective: (a) emotional exhaustion, (b) cynicism and (c) reduced personal efficacy. Emotional exhaustion is defined as a state when an individual feels emotionally worn-out. Cynicism is described as detachment, depersonalization from the work at hand, while reduced personal accomplishment is the state of feeling inadequate, and incapable of performing the task at hand (Maslach et al., 1996). Researchers (Goodman and Schorling, 2012) have studied various outcomes of burnout, including increased health problems, depression and reduced job performance. Some of the antecedents of burnout are job demand (Salanova et al., 2002; Bakker et al., 2005), disengagement (Peterson et al., 2008), stress (Lebares et al., 2018) and job characteristics (Bakker et al., 2005).

Researchers have argued that individuals with different personality types may experience varying degrees of burnout. For example, individuals with an external locus of control experience higher burnout in comparison to those with an internal locus of control (Wilski et al., 2015; Bitsadze and Japaridze, 2016). Realizing, understanding and accepting the present situation of the job will help in coping with burnout-related situations (Salanova et al., 2002; Bakker et al., 2005). Initial symptoms of burnout are indicated by an employee beginning to get the feeling of lack of control over events that will occur in the future (Wilski et al., 2015; Bitsadze and Japaridze, 2016). Mindfulness advocates focus on the current task by continuously monitoring the internal and external work environments (Chin et al., 2019). It is a state of "enhanced attention to and awareness of current experience or present reality" (Brown and Ryan, 2003, p. 822). Therefore, cultivating mindfulness will help individuals accept challenges one by one and respond without being judgemental (Goodman and Schorling, 2012).

H2 Mindfulness is negatively related to burnout

\section{Mindfulness and AC}

Trait-mindfulness consists of one's general propensity to act mindfully in every-day life. When employees are able to express their feeling towards job clearly and easily it is perceived that the employee has high aptitude for mindfulness, such person may remain committed to ones job (Harvey et al., 2015). Individual's understanding and acceptance about ones thoughts, emotions, and experiences at the present time without judging and controlling them is termed as mindfulness. The study of positive psychology found that variables that keep employees in a positive frame of mind and help in understanding the current working condition would result in having more commitment for the task at hand (Iglesias et al., 2019; Vandenberghe et al., 2017). Several antecedents like faculty knowledge sharing behaviour and supervisors role, have been studied by researchers to understand the effect on AC (Naeem et al., 2019; Vandenberghe et al., 2017). The positive association of mindfulness and commitment has been explained by mindfulness acceptance commitment-based approach (Gardner and Moore, 2004). Acceptance of current situation and commitment towards goal has been found to be helpful for students. Dionne (2016) found that the acceptance and commitment reduced the procrastination habit among students. Researchers have found that training on mindfulness has helped in improving mindfulness and commitment among teachers (Vogus and Sutcliffe, 2012). Therefore, possibility of positive relationship between teachers' high mindfulness quality with their commitment level is likely (Vogus and Sutcliffe, 2012). The affirmative feeling because of mindfulness will result in AC.

H3 Mindfulness is positively related to affective commitment

\section{The mediating role of employee voice behaviour}

Employee voice behaviour is a positive work behaviour variable, which is related to job performance and employee intent to leave (Luchak, 2003). It refers to openly raising issues and giving suggestions for improvement (Dyne et al., 2003; Maynes and Podsakoff, 2014). Speaking up about workplace issues is perceived as risky (Dyne et al., 2003). Therefore, employees who are genuinely focussed towards achieving the current goal will raise voice to correct hinderances by concentrating on 'what' is to be corrected rather than 'who' is to be corrected. The three types of voice behaviour identified by Dyne et al. (2003) are acquiescent voice, defensive voice and prosocial voice. The acquiescent voice is a disengaged behaviour where individual voice to agree with the group, not to make any difference. The second is defensive voice, which is a response to safeguard oneself; the individual perceive themselves at risk. Prosocial voice i.e, speaking up something constructive and voice that is intended to contribute positively to the organization. The prosocial voice behaviour indicates the altruistic behaviour of individuals where they are engaged in providing constructive ideas for the benefit of others in the organization. The constructive voice behaviour is the desired voice behaviour of employees in the organization.

Employees with a positive frame of mind will voice concerns for the growth of an individual and organization ( $\mathrm{Ng}$ et al., 2014). Mindfulness, as well as employee voice behaviour, are a positive psychological state (Peterson et al., 2011; Ng and Feldman, 2012). Therefore, employees with high mindfulness may create an environment conducive for voice behaviour and will be engaged in voicing important concerns (Good et al., 2016). Employees with a high level of mindfulness seemed to be balanced at the time of sharing and expressing opinions on toxic events (Bishop et al., 2004). Dunoon and Langer (2012), suggested that open communication and discussion of ideas and opinion is considered as a means to improve. Mindfulness and employee voice would instill self-belief and self- efficacy (Ucok, 2006). The scope for an employee to improve the job by listening to the ideas and changing it for improvement would lead to job satisfaction (Dunoon and Langer, 2012). Dunoon and Langer (2012) further state that the belief among employees that such behaviour is leading to self-growth, yields satisfaction. Thus, employee voice behaviour will mediate the positive relationship between mindfulness and job satisfaction.

Employee voice behaviour is considered as an oral expression of employees for constructive transformation, which is intended to improve the current state of affairs (Maynes and Podsakoff, 2014). The voice behaviour results in clarity of task and activities. Employee voice behaviour also indicates the interest of an individual in correcting issues at the current moment rather than delaying issues by not voicing it (Shepherd et al., 2019). The timing of employee voice behaviour is vital for the improvement of behaviour (Barry and Wilkinson, 2016). Timely correction of work would reduce the anxiety employees may experience at a later date, which may reduce burnout (Cordes and Dougherty, 1993). As proposed by Martin (1997), mindfulness prepares employees to use selective information by staying in the current situation and not getting perturbed by future uncontrollable situations. Mindful employees experiences reduced anxiety, depression and stress (Kasper, 2018). Thus, as suggested by Kasper (2018) individuals who practice mindfulness tend to mitigate a burnout situation before it will affect them adversely. Therefore, it is hypothesized that employee voice behaviour may 
mediate the negative relationship between mindfulness and burnout.

Similarly, the mediating effect of EVB between the positive relationship of mindfulness and $\mathrm{AC}$ was also tested. AC refers to the emotional attachment of employees with the organization (Shore and Wayne, 1993; Allen and Meyer, 1990). Researchers (Naeem et al., 2019; Vandenberghe et al., 2017) found that employees with high AC are found to identify themselves with the organization and enjoy being part of the organization. Employees with high mindfulness are found to have stable performance outcome (Dane and Brummel, 2014), critical learning (Espedal, 2009) and problem-solving attitude (Ostafin and Kassman, 2012). Dane and Brummel (2014) found that mindfulness improves effective engagement of employees with the task. It also helps in improved negotiation when employees raise voice for new ideas and opinions (Reb and Narayanan, 2014). Mindfulness improves voice behaviour by raising concerns, focussing attention to internal and external (multiple) information (Montani et al., 2018). Mindfulness and voice behaviour create a mechanism for employees to feel good (contended) about the job and organization and feel emotionally connected to it (Good et al., 2016). Maynes and Podsakoff (2014) raised concerns regarding the risk associated with voice behaviour. If employees perceive nonacceptance of voice behaviour by other co-workers, they may not be affectively committed. Therefore, it will be interesting to study the mediating effect of EVB on mindfulness and AC relationship.

H4 Employee voice behaviour mediates the positive and negative relationship between mindfulness and (a) faculty job satisfaction, (b) burnout and (c) affective commitment

\section{The moderating role of high-performance work systems}

High-performance work systems comprises of practices which promotes decision making by frontline employees, learning through training and development activities (Jeong and Shin, 2019). Jeong and Shin (2019) further stated that such practices promote open participation and useful contribution of employees in day-to-day work activities.

HPWS is creating a human resource practices sub-system that facilitates HR activities for the betterment of employees of the organization. Researchers (Delery and Doty, 1996) have studied HPWS from three different perspectives; universalistic perspective where certain $\mathrm{HR}$ practices are considered good for all organizations. Certain HR practices responds to the organizational strategy known as contingency perspective of HPWS. The configurational perspective demands presence of multiple HR practices interdependent on each other. The present study uses the configurational perspective to measure HPWS developed by Shih et al. (2006). The configurational perspective seemed appropriate, as the measure HPWS used two independent aspects infrastructure (basic HR practices) and job security. There is dearth of studies taking faculty members concerns in these areas. Researchers advocated that a group of complementary human resource practices, termed as HPWS, is better than stand-alone practices (Miao and Cao, 2019). HPWS creats a healthy and conducive internal ecosystem (Baik et al., 2019). HPWS was initially applied for a manufacturing setup based on the Japanese principle of job rotation and job enrichment (Womack et al., 1990). Later, the concept was also applied for a service industry like healthcare and IT sector (Ichniowski et al., 1997; Delery and Doty, 1996; Becker and Huselid, 1998). Very few reported studies have used the concept of HPWS in the higher education space (Combs et al., 2006). Higher education system though follows HR practices, do not have a separate HR department as found in business organizations. Teachers work in team and require training to perform well. The performance evaluation is based on

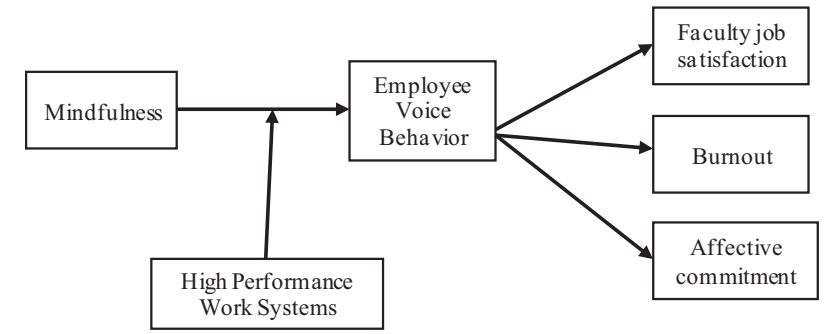

Fig. 1 Proposed model of the study. Mindfulness outcomes.

research output or teaching feedback. Therfore, such schools requires right infrastructure and job security of teachers to ensure high performance. The absence of HPWS will adversely affect the positive work outcomes.

Considering the organizational support theory, the employees perception regarding support provided to them by the organization, increases with the increase in perception about HPWS (Combs et al., 2006; Delery and Doty, 1996). Employee motivation is significantly related to outcome variables like job satisfaction and performance in the presence of HPWS (Eisenberger et al., 1986; Eisenberger and Stinglhamber, 2011; Messersmith et al., 2011). HPWS has also been found to influence employee attitudes (Takeuchi et al., 2009). Researchers like Macky and Boxall (2007) and Takeuchi et al. (2009) proposed to study individual attitudinal differences in organizations practicing HPWS. Therefore, the research has attempted to study the moderating effect of HPWS on mindfulness and AC relationship. $\mathrm{Wu}$ and Chaturvedi (2009) studied the positive effect of HPWS on job satisfaction. Researchers (Collins et al., 2001; Eisenberger and Stinglhamber, 2011) have argued regarding the positive employee outcomes (like performance, AC, job satisfaction) with good HR practices in the organization.

Macky and Boxall (2007) and Collins et al. (2001) proposed the role of HPWS in creating positive organizational behaviour in the organization. Employee mindfulness at the psychological level would concentrate on the current state of experience (Martin, 1997), which may be enhanced because of organizational practices, policies and ideologies that assure employees (Messersmith et al., 2011). Employees practicing mindfulness are considered to have effective and controlled emotional reactivity, self-awareness, and self-management (Brockman et al., 2017). The moderating effect of HPWS as a contextual variable would provide an answer to the questions regarding the contextual factors that promote mindfulness (Jeong and Shin, 2019). Therefore, the organization's decision to invest in sophisticated HR practices would facilitate enhancement in employees outcome, which is beneficial to the organization.

H5 HPWS moderates the positive and negative relationship between mindfulness and (a) faculty job satisfaction, (b) burnout, (c) affective commitment such that the relationships are stronger for respondents with high HPWS scores than respondents with low HPWS scores (Fig. 1).

\section{Methodology}

Study procedure. Data were collected from full-time faculty members of management schools of India. These schools were private, government-funded, autonomous or university-affiliated. The choice of the school was based on the list of top 100 schools appearing in the National Institutional Ranking Framework (NIRF) (2018), issued by the Ministry of Human Resource Development (MHRD), Government of India. Faculty members were first approached by an email indicating the objective and intent of the study. Emails of 1500 faculty members were identified after going through websites of each management schools 
and an email was sent to faculty members whose email id was listed on the website of the school. Faculty members from different functional areas like; marketing, finance, operations were chosen for the study. Two reminder emails were sent to encourage participation in the survey. Some faculty members could not take part in survey because of the criteria restriction. The qualifying criteria to be part of the survey included full-time association with the institute and affiliation of at least last one year with the institute. Emails were sent to those who qualify as per the information given on website. The qualifying criteria was also mentioned in the cover letter of the questionnaire. Part-time faculty and newly joined faculty did not form part of the sample. Participation in the survey was voluntary. The criteria were chosen to capture the right high-performance work systems data. Participants were apprised of the purpose of research and assured of anonymity.

Finally, 1092 usable data were received. Out of these, 489 were assistant professors, 398 were associate professors, and 205 were professors by designation. The average age of the respondents was 34.2 years. The average tenure of respondents was 6.8 years, and $63 \%$ of the respondents were male. Faculty members were highly qualified, with each interviewee possessing a Masters degree, and $72 \%$ of them either had a Ph.D. or equivalent degree or were perusing Ph.D.

\section{Measurement}

Mindfulness. Cognitive and Affective Mindfulness Scale-Revised (CAMS-R) was used to measure mindfulness. The scale was developed by Feldman et al. (2007). The original 12-item scale was revised to include only 10 items for further use in measurement. The items were measured on a 4-point rating scale. The Cronbach alpha value of the scale was 0.89 . Item six was reverse scored. Sum of all the item scores reflected greater mindful qualities.

High-performance work systems (HPWS). To measure HPWS, Shih et al. (2006), a 10-item questionnaire was used. The questionnaire was comprised of two factors: job infrastructure and job security. The responses were captured on a 5-point rating scale. The Cronbach alpha value of the questionnaire was 0.76. Sum of all the item scores indicated higher HPWS in the organization.

Employee voice behaviour. To measure employee voice behaviour Maynes and Podsakoff (2014) questionnaire was used. The questionnaire for constructive voice behaviour had five items, and the responses were collected on a 5-point rating scale. The Cronbach alpha value of the questionnaire was 0.91 . Sum of all the item scores reflected higher constructive employee voice behaviour.

Faculty job satisfaction. The scale developed by Victorino et al. (2018) was used to measure FJS. The scale had four items: satisfaction with department, institution, place of work and recommendation to the candidate. The items were measured on a 5-point scale. The Cronbach alpha value of the scale was 0.79 . Sum of all the item scores indicated perception of higher FJS.

Burnout. Maslach Burnout Inventory-General Survey (Maslach et al., 1996) was used to measure burnout. The questionnaire had three factors: emotional exhaustion, depersonalization and personal accomplishment. For the present study emotional exhaustion and depersonalization factors were used. The 14 items of the questionnaire were measured on a 5-point scale. The Cronbach alpha value of the scale was 0.93 . The sum of all the item scores reflected higher burnout.
Affective commitment. As per Allen and Meyer (1996), A 6-item scale was used to measure AC. The items were anchored on a 7point scale. The Cronbach alpha value of the questionnaire was 0.90. Sum of all the items indicated AC score.

Details of the measurement scale has been presented in Table 1 .

Control variables. Age, gender and tenure of faculty members were considered as control variables to understand the effect of independent variables on dependent variables. The variables were controlled on the premise that a positive relationship was reported by several researchers between age, tenure and mindfulness (Hohaus and Spark, 2013; Valentine et al., 2010; Eisenbeiss and van Knippenberg, 2015). Faculty members with higher age and tenure in the institute may not get perturbedby the demanding circumstances of higher education because of experience and familiarity with the profile. Mindfulness scores on the CAMS-R showed small associations with age $(r=0.13, \mathrm{~ns})$ and gender $(r=0.19, p=0.007)$. Men showed relatively better score on mindfulness than female (Feldman et al., 2007). In our sample the percentage of male was more than female. Hence, age, gender and tenure of faculty members were controlled.

Common method variance. To examine data for common method variance, three different steps were taken. Firstly, questionnaire was distributed at two different time interval. Data on independent variables like mindfulness, HPWS and Employee voice vehaviour were collected at time 1 with google form 1 and data on dependent variables like FJS, burnout and AC were collected at time 2 with google form 2 . Time 1 and 2 had more than 15 days time interval. A google form was sent via email to each respondent. The first form was opened in the first attempt and 15 days later the second form was opened by the respondents. In the time 1 and time 2 respondents were same. The merging of data of independent variables from time 1 and dependent variables from time 2 were done so that the tendency to give similar pattern of responses can be minimized if complete questionnaire is filled at a go. The data were further subjected to analysis of variance to check the differences in the two set of data collected at time 1 and time 2. The non-significant difference $(F=1.24, p<$ 0.10 ) of data from time 1 and 2 indicated that the data can be merged for further analysis. Harman's single factor test was applied to the variables under study. Podsakoff et al. (2003) advocated that CMV is considered to be high if the data will be heavily loaded on a single factor and will explain significant variance. The factor analysis results were satisfactory, resulting in multiple factors. The first factor accounted for $23 \%$ of the variance. Further, confirmatory factor analysis was conducted to understand the goodness of fit for the six-factor model versus the one-factor model. The analysis helped in reinforcing the fact that variables were perceived distinctively by respondents. The sixfactor model comprising of mindfulness, HPWS, employee voice behaviour, FJS, AC, and burnout resulted in better model fit values $\left(\chi^{2}-1219, p=0.10\right.$, df-520, GFI-0.92, AGFI-0.90, NFI-0.93, CFI-0.93, RMSEA-0.04) in comparison to five, four, three, two and one factor models (Table 2).

\section{Results}

Descriptive statistics and intercorrelations between variables under study are presented in Table 3. Descriptive statistics helped in understanding the respondent's characteristics while the intercorrelation matrix provided the direction of the relationship between variables, which formed the base for the exploration of hypotheses. 


\section{Table 1 Details of questionnaire used for the study.}

\section{Variable construct}

Factors

\section{Mindfulness}

It is easy for me to concentrate on what I am doing.

I can tolerate emotional pain.

I can accept things I cannot change.

I can usually describe how I feel at the moment in considerable

detail.

I am easily distracted $(R)$.

It's easy for me to keep track of my thoughts and feelings.

I try to notice my thoughts without judging them.

I am able to accept the thoughts and feelings I have.

I am able to focus on the present moment.

I am able to pay close attention to one thing for a long period

of time.

Employee voice behaviour

Constructive voice behaviour

Frequently makes suggestions about how to do things in new or more effective ways at work.

Often suggests changes to work projects in order to make them better.

Often speaks up with recommendations about how to fix work- related problems.

Frequently makes suggestions about how to improve work methods or practices.

Regularly proposes ideas for new or more effective work methods.

High performance work system

Job infrastructure

My organization involves us in Team work

My organization encourages Workers' involvement in problem solving

My organization encourages Information sharing

My organization encourages Performance-based promotion

My organization encourages Performance-based pay

My organization encourages Team-based job design

My organization encourages Comprehensive training

My organization encourages Formal training

Job security

My organization has Commitments of no lay off

My organization Won't use lay off to cut down cost

Affective commitment

I feel strong sense of belonging to my organization

I feel personally attached to my organization

I am proud to tell others I work at my organization

Working at my organization has a great deal of personal

meaning to me

I would be happy to work at my organization until I retire

I really feel that problems faced by my organization are also

my problems

Faculty Job Satisfaction

I am satisfied with my department

I am satisfied with my institution

I recommend a candidate for a tenure-track position at my department

Rate the institution as place to work

Burnout

Depersonalization

I feel I treat some recipients as if they were impersonal 'objects'.

I've become more callous toward people since I took

this job.

I worry that this job is hardening me emotionally.

I don't really care what happens to some recipients.

I feel recipients blame me for some of their problems.

Emotional exhaustion

I feel emotionally drained from my work.

I feel used up at the end of the workday.

Researchers proposed four types of employee voice behaviour; Supportive, constructive, defensive, and destructive. In the present study constructive voice behaviour was measured.

Two factors were measured Job infrastructure and Job security

The complete scale has three factors; affective, normative and continuance commitment. The present paper has used only affective commitment

Authors presented three factors personal accomplishment, depersonalization and emotional exhaustion. The current paper used burnout as a negative construct, therefore, used two factors depersonalization and emotional exhaustion for measures. 


\section{Table 1 (continued)}

\section{Variable construct}

\section{Factors}

I feel fatigued when I get up in the morning and have to face

another day on the job.

Working with people all day is really a strain for me.

I feel burned out from my work.

I feel frustrated by my job.

I feel I'm working too hard on my job.

Working with people directly puts too much stress on me.

I feel like I'm at the end of my rope.

Table 2 Measurement model confirmatory factor analysis.

\begin{tabular}{lllllllll} 
Measurement model & $\chi^{\mathbf{2}}$ & Sig. & df & GFI & AGFI & NFI & CFI & RMSEA \\
\hline One factor model & 8382 & 0.29 & 723 & 0.59 & 0.40 & 0.55 & 0.54 & 0.321 \\
Two factor model & 7172 & 0.18 & 722 & 0.63 & 0.52 & 0.60 & 0.61 & 0.282 \\
Three factor model & 6756 & 0.15 & 721 & 0.68 & 0.59 & 0.63 & 0.62 & 0.191 \\
Four factor model & 4122 & 0.14 & 720 & 0.72 & 0.66 & 0.69 & 0.70 & 0.120 \\
Five factor model & 2987 & 0.12 & 719 & 0.89 & 0.83 & 0.82 & 0.82 & 0.081 \\
Six factor model & 1219 & 0.10 & 520 & 0.92 & 0.90 & 0.93 & 0.93 & 0.04
\end{tabular}

The six-factor model considered all the variables as independent factors. In the six-factor model, mindfulness and EVB items were combined and loaded on one factor. In the four-factor model mindfulness, EVB and HPWS items were loaded on one factor. In the three-factor model, the items of mindfulness, EVB, HPWS, and FJS were loaded on one factor. In the two-factor model items of mindfulness, EVB, HPWS, FJS, and affective commitment were loaded on one factor. Finally, in the one-factor model, all the items were loaded on a single factor.

GFI goodness of the fit index, AGFI adjusted goodness of fit index, NFI normed fit index, CFI comparative fit index, RMSEA root mean square error of approximation.

\section{Table 3 Results of descriptive and correlation analysis.}

\begin{tabular}{|c|c|c|c|c|c|c|c|c|c|c|c|}
\hline Variables & $M$ & SD & 1 & 2 & 3 & 4 & 5 & 6 & 7 & 8 & 9 \\
\hline 1 Age & 34.2 & 7.3 & 1 & & & & & & & & \\
\hline 2 Gender & 0.63 & 0.29 & $0.32^{\star \star}$ & 1 & & & & & & & \\
\hline 3 Tenure & 6.81 & 5.2 & $0.41^{\star \star}$ & $0.17^{\star \star}$ & 1 & & & & & & \\
\hline $5 \mathrm{EVB}$ & 4.0 & 2.17 & $0.13^{\star}$ & $0.11^{\star}$ & $0.31^{\star \star}$ & $0.41^{\star \star}$ & $(0.91)$ & & & & \\
\hline 6 HPWS & 3.12 & 2.01 & $0.26^{\star \star}$ & $0.15^{\star}$ & $0.25^{\star \star}$ & $0.47^{\star \star}$ & $0.63^{\star \star}$ & $(0.76)$ & & & \\
\hline 7 FJS & 4.43 & 3.5 & $0.19^{\star \star}$ & $0.13^{\star}$ & $0.28^{\star \star}$ & $0.43^{\star \star}$ & $0.39^{\star \star}$ & $0.50^{\star \star}$ & $(0.79)$ & & \\
\hline
\end{tabular}

$N=1092$, Cronbach's alpha values are given in the parentheses.

${ }^{\star *} p<0.01 ;{ }^{*} p<0.05$

EVB employee voice behaviour, HPWS high-performance work systems, FJS faculty job satisfaction.

\section{Table 4 Hierarchcal regression analysis.}

\begin{tabular}{|c|c|c|c|c|c|c|c|c|c|c|}
\hline \multirow[b]{2}{*}{ Variables } & \multirow[b]{2}{*}{ EVB } & Step1 & Step 2 & Step 3 & Step1 & Step 2 & Step 3 & Step1 & Step 2 & Step 3 \\
\hline & & \multicolumn{2}{|c|}{ Affective Commitment } & \multicolumn{3}{|c|}{ Buronout } & \multicolumn{4}{|c|}{ Job Satisfaction } \\
\hline Gender & 0.07 & $0.10^{\star}$ & 0.03 & 0.05 & $0.10^{\star}$ & $0.11^{\star}$ & $0.13^{\star}$ & 0.08 & 0.03 & 0.07 \\
\hline Tenure & $0.18^{\star \star}$ & $0.17^{\star \star}$ & $0.11^{\star}$ & $0.11^{\star}$ & $0.11^{\star}$ & $0.11^{\star}$ & $0.10^{\star}$ & $0.14^{\star \star}$ & $0.14^{\star}$ & $0.13^{\star}$ \\
\hline Mindfulness & $0.62^{\star \star}$ & $0.27^{\star \star}$ & & $0.54^{\star \star}$ & -0.09 & & $-0.21^{\star \star}$ & $0.21^{\star \star}$ & & $0.38^{\star \star}$ \\
\hline EVB & & & $0.66^{\star \star}$ & $0.22^{\star \star}$ & & $-0.36^{\star \star}$ & $-0.23^{\star \star}$ & & $0.43^{\star \star}$ & $0.26^{\star \star}$ \\
\hline
\end{tabular}

Direct and mediation effect. To test the direct and indirect relationship Hayes SPSS PROCESS macro was used (Hayes, 2013; Preacher and Hayes, 2008). The Hayes macro is useful in testing the mediation model, moderation model and conditional process analysis. The effect of mindfulness was positively related to FJS $(\beta=0.38 ; p \leq 0.01)$, negatively related to burnout $(\beta=-0.21 ; p \leq$ $0.01)$, and positively related to $\mathrm{AC}(\beta=0.54 ; p \leq 0.01)$. The findings supported Hypotheses 1, 2, and 3, respectively. Mindfulness was significantly related to $\operatorname{EVB}(\beta=0.62 ; p \leq 0.01)$ and EVB was significantly related to FJS $(\beta=0.43 ; p \leq 0.01)$, burnout $(\beta=-0.36 ; p \leq 0.01)$, and $\mathrm{AC}(\beta=0.66 ; p \leq 0.01)$ (Table 4$)$.

To further test the mediation relation hierarchical regression analysis was used (Aiken et al., 1991). The indirect effect of mindfulness on FJS $(\beta=0.21 ; p \leq 0.01)$, burnout $(\beta=-0.09 ; p \leq$ 


\begin{tabular}{|lccl|}
\hline \multicolumn{3}{|l|}{ Table 5 Results of moderating effects of HPWS. } \\
Main effects & $\begin{array}{l}\text { Faculty job } \\
\text { satisfaction }\end{array}$ & Burnout & $\begin{array}{l}\text { Affective } \\
\text { commitment }\end{array}$ \\
\hline Mindfulness & $0.12^{\star}$ & $-0.17^{\star}$ & $0.25^{\star \star}$ \\
High performance & $0.32^{\star \star}$ & $-0.15^{\star}$ & $0.35^{\star \star}$ \\
work systems & & 0.12 & 0.15 \\
$R^{2}$ & 0.17 & $29.7^{\star \star}$ & $22.83^{\star \star}$ \\
$F$ & $42.3^{\star \star}$ & -0.10 & $0.27^{\star \star}$ \\
Interaction effect & & 0.162 & 0.161 \\
Mindfulness $\times$ HPWS & $0.41^{\star \star}$ & $16.23^{\star \star}$ & $19.13^{\star \star}$ \\
$R^{2}$ & 0.183 & & \\
$F$ & $18.1^{\star \star}$ & & \\
\hline${ }^{\star \star} p=0.01,{ }^{*} p=0.05$. & & & \\
\hline
\end{tabular}

$0.07)$ and $\mathrm{AC}(\beta=0.27 ; p \leq 0.01)$, were tested and were found to be significant. The significant $\beta$ values indicated mediation of EVB between mindfulness, FJS, AC and burnout relationship (Table 4). The significance of the indirect effect was further tested using Sobel's (1982) test. The data was bootstrapped with 5000 replications at a $95 \%$ confidence interval. The significant values indicated EVB-mediated mindfulness-FJS $(z=6.13, p \leq 0.01)$, mindfulness-burnout $(z=-11.01, p \leq 0.01)$ and mindfulnessAC $(z=5.12, p \leq 0.01)$ relationships. The results supported EVB as a mediator (hypotheses $4 a-c$ ).

Moderation effect. To test hypothesis $5 \mathrm{a}-\mathrm{c}$ regarding moderation effect of HPWS, conditional process analysis was. The main effect of mindfulness on FJS $(\beta=0.12, p \leq 0.05)$, burnout $(\beta=-0.17$, $p \leq 0.05)$, and $\mathrm{AC}(\beta=0.25, p \leq 0.01)$, and the main effect of HPWS on FJS $(\beta=0.32, p \leq 0.01)$, burnout $(\beta=-0.15, p \leq 0.05)$, and $\mathrm{AC}(\beta=0.35, p \leq 0.01)$ were weaker than the interaction effect. The interaction effect of mindfulness and HPWS had significant $\beta$ values on FJS $(\beta=0.41, p \leq 0.01)$, on burnout $(\beta=-0.10, p \leq 0.05)$ and on $\mathrm{AC}(\beta=0.30, p \leq 0.01)$ (Table 5$)$. The conditional moderating effects of HPWS on mediation relationships were also significant. The bootstrap results indicated confirmation of the findings as the results of confidence intervals did not have a range with zero for mindfulness. The effect size were found to be high and significant for high HPWS in comparison to low HPWS for AC (effect size $=0.112$; $\mathrm{LLCI}=0.0465-\mathrm{ULCI}=0.009), \quad \mathrm{BO} \quad($ effect $\quad$ size $=-0.10$; $\mathrm{LLCI}=-0.012-\mathrm{ULCI}=-0.008)$ and FJS (effect size $=0.159$; LLCI $=0.0652-\mathrm{ULCI}=0.0039$ ). Higher and significant beta values of the interaction effect and significant effect size of conditional moderation, confirmed the moderating effect of HPWS, supporting hypothesis $5 \mathrm{a}-\mathrm{c}$. The conditional moderated regression results are presented in Table 6 . The interaction effects to confirm moderation are presented in Fig. 2a-c. The slope of the lines indicated that the relationships were stronger for faculty members who experienced greater HPWS than those who experienced lower HPWS.

\section{Discussion}

Researchers have advocated the influence of positive behaviour on individual outcomes (Dane and Brummel, 2014; Alonderiene and Majauskaite, 2016). Extending similar studies, this study introduced a contextual variable, HPWS, to understand the mechanism involved in changing outcome variables because of the presence or absence of HPWS. The role of teachers have been noted as important in developing student learning and social emotional well-being. Teachers are under pressure because of changing corporate demands and to prepare students for the same, at the same time teachers are also required to cater to

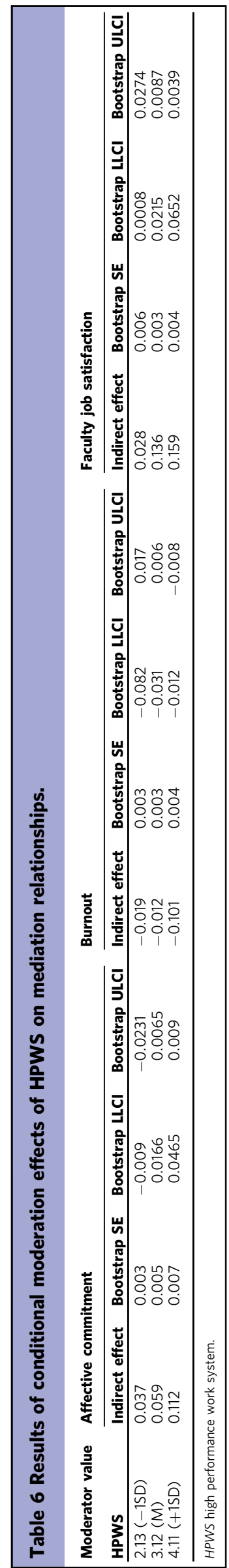



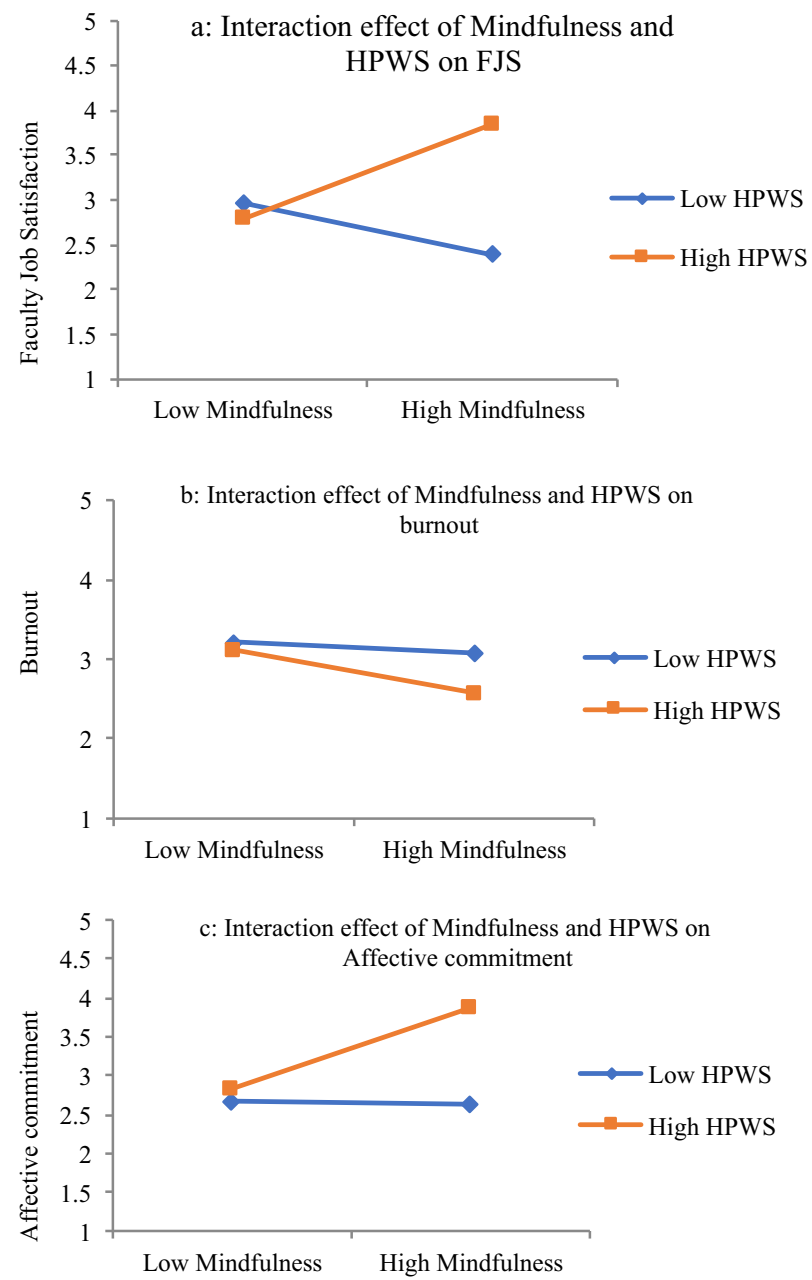

Fig. 2 Interaction effect mindfulness and HPWS on outcome variables. a Interaction effect of Mindfulness and HPWS on FJS. $\mathbf{b}$ Interaction effect of Mindfulness and HPWS on burnout. $\mathbf{c}$ Interaction effect of Mindfulness and HPWS on Affective commitment.

students' requirements patiently. Such environment add to a lot of stress on teachers of higher education, still most of the schools fail to address the concern. Researchers have focused on mindfulness intervention important for students, but studies considering teachers are a few. For the teachers of higher education it is important to understand the degree of mindfulness present among faculty members. Faculty with less indication of such traits may undergo mindfulness intervention for the benefit of self and the management school. Researchers have studied that faculty members with higher trait of mindfulness or having gone through mindfulness awareness program experiences reduced stress, anxiety and burnout.

The study has many significant contributions. First, the paper studied the effect of mindfulness from the perspective of higher education faculty, which has not been reported earlier. It is of significant importance, as several recent studies have reported the occurrence of stress (Andrews et al., 2014; Antony and Valadez, 2002) among faculty members because of non-clarity in self-goal and institute's long-term direction. Mindfulness that focusses on being at the current state and understanding the difference between controllable and non-controllable factors (Darvas, 2018; Atkinson and Wade, 2019), was an active contributor in the present study. Though age, gender and tenure were control variables, a preliminary analysis was in line with previous findings. Age and tenure were positively related to mindfulness while gender had no effect on mindfulness practices.

The research studied the relationship between mindfulness and job satisfaction. Job satisfaction has been traditionally studied from the extrinsic monetary (pay and reward) perspective (Krueger et al., 2017; Trivellas and Santouridis, 2016). The present research studied job satisfaction with respect to factors like satisfaction with the department, institution, work and whether faculty members would recommend the institute to students or not. The significant relationship between mindfulness and job satisfaction indicates that a faculty member practicing mindfulness would be satisfied with the school at its current state. The respondents indicated that they were neither carrying the institute's history in their mind nor were did they worry about future conditions to like or dislike the institute. Therefore, the significant relationship is in congruence with the findings of Bachman (1968) and Victorino et al. (2018) who stated the importance of more stable job satisfaction if the awareness and acceptance of the current state are acknowledged.

The study contributed by studying the negative relationship between mindfulness and burnout. The study is in line with the findings of researchers like Wilski et al. (2015) and Bitsadze and Japaridze (2016) who advocated personality characteristics like core self-evaluation and extraversion having a negative relationship with burnout. This led to the need to further explore positive psychological behaviour as antecedents of burnout. Studies have reported imbalance of job demands and resource allocation as a primary reason for employees' burnout (Salanova et al., 2002; Bakker et al., 2005; Pines, 2017). In the recent past, a growing number of researchers have studied the effect of burnout on affective outcomes like commitment, involvement and satisfaction. Bakker et al. (2005) found the negative effect of burnout on job performance. This study extends the earlier findings and advocates that the psychological states may sometimes be controlled by external factors (job demand, resource allocation or superior support) (Lebares et al., 2018), though it is primarily governed by internal factors like (emotional intelligence, depersonalization and lowered sense of self efficacy) (Maslach et al., 1996). Therefore, the finding advocating a negative relationship between mindfulness and burnout is justifiable. Faculty members practicing mindfulness may experience less burnout because of better emotional and self control.

The third hypothesis regarding mindfulness and AC filled the gap regarding the AC mechanism (Lee and Corbett, 2006; Naeem et al., 2019). If mindfulness results in the desired transformation in faculty members' day-to-day routine experiences, their AC towards their job will increase. To explain this further, Swanson and Ramiller (2004) distinguished mindfulness and mindlessness and its effect on organizational innovation. To enhance mindfulness employees are trained to focus their attention on exercise (usually breathing exercise) and being aware of every instant. Mindfulness, as explained by Cheung (2018), is divided into three stages: thoughts, sensation and feelings. The feeling level of mindfulness that focuses on immediate and long-term changes in the temperament would influence AC positively (Cheung, 2018). Employees practicing mindfulness would be more emotionally mature and would be affectively connected to the task at hand.

The study of employee voice behaviour as a mediator is another significant contribution to the study. Employee voice behaviour is a positive organizational behaviour while extra-role behaviour has been found to influence individual outcomes significantly (Ng et al., 2014). According to Dyne et al. (2003), employee voice behaviour is a productive form of raising issues, which needs improvement. Given today's work environment where many millennials work, it is essential for them to know and share information (Frank et al., 2017). As suggested by Good et al. 
(2016), millennials have access to information, which helps them in constructing their concerns in a structured form and raise the issue. Similarly, the sample of this study that comprises of management faculty are intellectuals who value their profession because of the opportunity to speak and raise concerns constructively. Therefore, in this study, EVB has played a mediating role between mindfulness and outcome variables such as job satisfaction, burnout and AC.

Our study supported the findings of Engemann and Scott (2018), which reported that employees who practice mindfulness would view raising concerns and issues as their responsibility. The creative voice will provide the opportunity to correct the job at hand and improve (Bishop et al., 2004). The gradual improvement in the job will bring job satisfaction. Similarly, Pines (2017) found that employee voice behaviour will facilitate low burnout among faculty members as the higher education system is an example of a flat organization structure where communication flows freely and does not promote hierarchy. The flat, non-hierarchical structure enables employees to voice their concerns without obstructions. At the same time, mindfulness will control the harmful voice behaviour and will minimize the feeling of risk associated with voice behaviour (Oeij et al., 2018), which reduces stress and burnout. Employees are more committed to the job when they are free to raise concerns if required. It goes with an understanding that the one who raises concerns and wishes to correct things, feels positively for the job. Brown et al. (2005) suggested that employees who believe in EVB demonstrate superior engagement and belongingness with the firm, and such employees raise ethical concerns. Therefore, our findings regarding employee voice behaviour contributed to the EVB literature and extended it for the faculty of higher education (management), where autonomy and freedom of expression have been accepted as theculture of an institute (Stupnisky et al., 2018; Schwind et al., 2017).

By studying the contextual moderator variable, HPWS, the study contributes to highlighting the underlying mechanism of the mindfulness-outcome relationship. The study examined the positive and negative interactive effects of mindfulness and HPWS on outcome variables. Well-defined HR practices of organizations creates a productive environment for employees. HR practices under HPWS are aligned to organizational goals, which can understand the immediate need of employees and respond to the crisis before it spreads negativity. Eisenberger and Stinglhamber (2011) supported the fact that availability of resources and proper infrastructure would facilitate work at the organization. Similarly, employees with job security and without any fear of losing job work more effectively and remain stress-free (Shih et al., 2006). Messersmith et al. (2011) found that the organization's effort in training their employees and conducting fair appraisal has resulted in high AC. The career growth plans that HPWS promote reduce the feeling of bias among members (Jeong and Shin, 2019). Therefore, well-defined HR infrastructure as a component of HPWS encourages confidence among employees to raise constructive voice and enhance the positivity of mindfulness behaviour. An appropriate working environment and positive work behaviour would enable a positive work outcome, thus, supporting the role of HPWS as moderator.

Practical implications. The impact of mindfulness was studied on outcome variables which were mediated by employee voice behaviour and moderated by high-performance work systems. The practice of mindfulness is effective where different generations meet and solve issues unique to each generation (Lynch et al., 2011; de Bruin et al., 2015). Higher education is one such area where students and faculty (from same and different generations and from diverse backgrounds) meet to increase the value proposition (Schwind et al., 2017; Malouf et al., 2017). Therefore, the study has many practical implications.

The mediating relationship of employee voice behaviour indicates the need for shared view, collaboration, discussion and open forum for suggestion and idea-sharing in the domain of higher education (Knight, 2015; Darvas, 2018). Faculty members who constructively voice issues may create a stress free satisfied environment and management schools therefore, should promote such behaviour. The constructive voice behaviour will facilitate any change process that school is going through. This is because of constructive ideas, process change and presence of committed and satisfied employees. Higher education institutions in India shall be open for constructive communication and a healthy work culture so that the employee's voice is heard not only for individual benefit but also for the larger good (Tuckey et al., 2018; Zivnuska et al., 2016).

Findings of the study reveal that the outcomes of mindfulness are not immediate or direct (O'Reilly, 1998). Its awareness prepares individuals to respond, raise and debate about the current state of affairs (Bush, 2011). It also prepares employees (faculty members) for uncertainties, imbalances and vulnerability the future economy presents in front of us. The study acknowledges that any school is a combination of individual personalities and systemic integration. The findings of this study acknowledged the role HR practices play in creating committed, stress-free, satisfied employees (Michel et al., 2014; Saavedra et al., 2010; Cheung, 2018). HPWS is one such set of HR practices that ensure fair treatment of employees, leading to regular development in vertical (Cheung, 2018) as well as horizontal growth where the breath of knowledge of employees increases by practicing job enrichment and delegation.

Limitations and future scope. The study is not without limitations despite listing contributions. First, it uses only the higher education management faculty as a sample. The study would be more generalizable if another discipline of higher education like arts, science or engineering is included. However, management education and faculty members are closer to corporate requirements (Bennett et al., 2018) and hence, appropriate as the choice of sample. Second, the cross-sectional research design restricted the richness of information required for analysis. Mindfulness as a variable may take some practice and matures over time (Langer, 1998). Future researchers can experiment with longitudinal data to arrive at sound inferences based on the results. Thirdly, the data were collected using email, which restricted it to two different time intervals, resulting in possible common method variance. Though statistical measures were taken to control CMV, future researchers may improve procedural requirements by personally administering the questionnaire and by increasing the time gap between two intervals, while collecting data. Finally, the study was about faculty members teaching in varouus management schools of India. A similar study involving cross-cultural samples from developed nations or nations ranked top 10 in the happiness index (Li, 2018) may yield valuable insights. Future researchers can test different outcome variables keeping EVB as a mediator and HPWS as a moderator in different work settings.

\section{Data availability}

The datasets generated during and/or analysed during the current study are not publicly available due confidentiality agreement with participants, but are available from the corresponding author on reasonable request. 
Received: 28 April 2020; Accepted: 10 November 2020;

Published online: 27 January 2021

\section{References}

Aiken LS, West SG, Reno RR (1991). Multiple regression: testing and interpreting interactions. Sage

Allen NJ, Meyer JP (1996) Affective, continuance, and normative commitment to the organization: an examination of construct validity. J Vocat Behav 49:252-276

Allen N, Meyer JP (1990) The measurement and antecedents of affective, continuance and normative commitment to the organization. J Occup Psychol 63:1-18

Alonderiene R, Majauskaite M (2016) Leadership style and job satisfaction in higher education institutions. Int J Educ Manag 30:140-164

Andrews CM, Michele Kacmar K, Kacmar C (2014) The mediational effect of regulatory focus on the relationships between mindfulness and job satisfaction and turnover intentions. Career Dev Int 19:494-507

Antony JS, Valadez JR (2002) Exploring the satisfaction of part-time college faculty in the United States. Rev High Educ 26:41-56

Atkinson M, Wade TD (2019) Mindfulness training. In: Piran, N \& T Tylka, Handbook of positive body image and embodiment: constructs, protective factors, and interventions. Oxford University Press

Bachman JG (1968) Faculty satisfaction and the dean's influence: an organizational study of twelve liberal arts colleges. J Appl Psychol 52:55-61

Baik K, Kim KY, Patel PC (2019) The internal ecosystem of high-performance work system and employee service-providing capability: a contingency approach for servitizing firms. J Bus Res 104:402-410

Bakker AB, Demerouti E, Euwema MC (2005) Job resources buffer the impact of job demands on burnout. J Occup Health Psychol 10:170

Barry M, Wilkinson A (2016) Pro-social or pro-management? A critique of the conception of employee voice as a pro-social behaviour within organizational behaviour. Br J Ind Relat 54:261-284

Becker E, Huselid MA (1998) High performance work systems and firm performance: A synthesis of research and managerial implications. Res Pers Hum Resour Manag 16:53-101

Bennett RI, Egan H, Cook A, Mantzios M (2018) Mindfulness as an intervention for recalling information from a lecture as a measure of academic performance in higher education: a randomized experiment. High Educ Future $5: 75-88$

Berila B (2015) Integrating mindfulness into anti-oppression pedagogy: social justice in higher education. Routledge

Bishop SR, Lau M, Shapiro S, Carlson L, Anderson ND, Carmody J, Abbey S, Speca M, Velting D, Devins G (2004) Mindfulness: a proposed operational definition. Clin Psycholy: Sci Pract 11:230-241

Bitsadze M, Japaridze M (2016) Locus of control in Georgian teachers and its relation to teacher burnout. Problems of Management in the 21st Century 11:8-15

Brockman R, Ciarrochi J, Parker P, Kashdan T (2017) Emotion regulation strategies in daily life: mindfulness, cognitive reappraisal and emotion suppression. Cogn Behav Ther 46:91-113

Brown KW, Ryan RM (2003) The benefits of being present: mindfulness and its role in psychological well-being. J Personal Soc Psychol 84:822

Brown ME, Treviño LK, Harrison DA (2005) Ethical leadership: a social learning perspective for construct development and testing. Organ Behav Hum Decision Process 97:117-134

Bush M (2011) Mindfulness in higher education. Contemp Buddhism 12:183-197 Cheung LKG (2018) Demystifying buddhist mindfulness: Foundational buddhist knowledge for mindfulness-based interventions. Spiritual Clin Pract 5(3):218

Chin B, Slutsky J, Raye J, Creswell JD (2019) Mindfulness training reduces stress at work: a randomized controlled trial. Mindfulness 10:627-638

Collard P, Avny N, Boniwell I (2008) Teaching mindfulness based cognitive therapy (MBCT) to students: the effects of MBCT on the levels of mindfulness and subjective well-being. Couns Psychol Q 21:323-336

Collins CJ, Smith, KG, Stevens CK (2001) Human resource practices, knowledgecreation capability and performance in high technology firms. CAHRS Working Paper Series, 65

Combs J, Liu Y, Hall A, Ketchen D (2006) How much do high-performance work practices matter? A meta-analysis of their effects on organizational performance. Pers Psychol 59:501-528

Cordes CL, Dougherty TW (1993) A review and an integration of research on job burnout. Acad Manag Rev 18:621-656

Dahlgaard J, Jørgensen MM, van der Velden AM, Sumbundu A, Gregersen N, Olsen RK, Mehlsen MY (2019) Mindfulness, health, and longevity. In: The science of hormesis in health and longevity. Academic Press, pp. 243-255
Dane E, Brummel BJ (2014) Examining workplace mindfulness and its relations to job performance and turnover intention. Hum Relat 67:105-128

Darvas P (2018) Governmental reforms in hungarian higher education: historical traditions and Nezv actors. In: Reform and change in higher education Routledge, pp. 245-286

de Bruin EI, Meppelink R, Bögels SM (2015) Mindfulness in higher education: awareness and attention in university students increase during and after participation in a mindfulness curriculum course. Mindfulness 6:1137-1142

Delery JE, Doty DH (1996) Modes of theorizing in strategic human resource management: tests of universalistic, contingency, and configurational performance predictions. Acad Manag J 39:802-835

Dionne F (2016) Using acceptance and mindfulness to reduce procrastination among university students: results from a pilot study. Rev Prâksis 1:8-20

Dunoon D, Langer E (2012) Mindful leadership communication: three keys for action. Train Dev 39:12

Dyne LV, Ang S, Botero IC (2003) Conceptualizing employee silence and employee voice as multidimensional constructs. J Manag Stud 40:1359-1392

Eby LT, Allen TD, Conley KM, Williamson RL, Henderson TG, Mancini VS (2019) Mindfulness-based training interventions for employees: a qualitative review of the literature. Hum Resource Manag Rev 29:156-178

Eisenbeiss SA, van Knippenberg D (2015) On ethical leadership impact: the role of follower mindfulness and moral emotions. J Organ Behav 36:182-195

Eisenberger R, Stinglhamber F (2011) Perceived organizational support: fostering enthusiastic and productive employees. American Psychological Association. https://doi.org/10.1037/12318-000

Eisenberger R, Huntington R, Hutchison S, Sowa D (1986) Perceived organizational support. J Appl Psychol 71:500

Engemann KN, Scott CW (2018) Voice in safety-oriented organizations: examining the intersection of hierarchical and mindful social contexts. Hum Resource Manag Rev 30(1):100650

Espedal B (2009) Maneuvering space for leadership. J Leadersh Organ Stud $16: 197-212$

Feldman G, Hayes A, Kumar S, Greeson J, Laurenceau JP (2007) Mindfulness and emotion regulation: the development and initial validation of the Cognitive and Affective Mindfulness Scale-Revised (CAMS-R). J Psychopathol Behav Assess 29:177

Frank JL, Kohler K, Peal A, Bose B (2017) Effectiveness of a school-based yoga program on adolescent mental health and school performance: Findings from a randomized controlled trial. Mindfulness 8:544-553

Gardner FL, Moore ZE (2004) A mindfulness-acceptance-commitment-based approach to athletic performance enhancement: theoretical considerations. Behav Ther 35:707-723

Glomb TM, Duffy MK, Bono JE, Yang T (2011) Mindfulness at work. In: A Joshi, H Liao, \& JJ Martocchio (Eds), Research in personnel and human resources management. Emerald Group Publishing Limited, pp. 115-157

Good DJ, Lyddy CJ, Glomb TM, Bono JE, Brown KW, Duffy MK, Baer RA, Brewer JA, Lazar SW (2016) Contemplating mindfulness at work: an integrative review. J Manag 42:114-142

Goodman MJ, Schorling JB (2012) A mindfulness course decreases burnout and improves well-being among healthcare providers. Int J Psychiatry Med 43:119-128

Gunaratna BH (2002) Mindfulness in plain English. Wisdom Publications, Boston Hayes AF (2013) The PROCESS macro for SPSS and SAS (version 2.13) [Software]

Harvey J, Knowles, Manusov V, Crowley J (2015) Minding your matters: Predicting satisfaction, commitment, and conflict strategies from trait mindfulness. PsychOpen, 2015... JP Crowley. Int Encycl Interpers Commun 5:1-6

Herzberg F (1968) One more time: how do you motivate employees? Harv Bus Rev 40:53-62

Hohaus LC, Spark J (2013) 2672-Getting better with age: do mindfulness \& psychological well-being improve in old age? Eur Psychiatry 28:1

Hölzel BK, Lazar SW, Gard T, Schuman-Olivier Z, Vago DR, Ott U (2011) How does mindfulness meditation work? Proposing mechanisms of action from a conceptual and neural perspective. Perspect Psychol Sci 6:537-59.

Hülsheger UR, Alberts HJ, Feinholdt A, Lang JW (2013) Benefits of mindfulness at work: the role of mindfulness in emotion regulation, emotional exhaustion, and job satisfaction. J Appl Psychol 98:310

Ichniowski C, Shaw K, Prennushi G (1997) The effects of human resource practices on manufacturing performance: a study of steel finishing lines. Am Econ Rev 87:291-313

Iglesias O, Markovic S, Rialp J (2019) How does sensory brand experience influence brand equity? Considering the roles of customer satisfaction, customer affective commitment, and employee empathy. J Bus Res 96:343-354

Jeong I, Shin SJ (2019) High-performance work practices and organizational creativity during organizational change: a collective learning perspective. J Manag 45:909-925

Jiang K, Lepak DP, Hu J, Baer JC (2012) How does human resource management influence organizational outcomes? A meta-analytic investigation of mediating mechanisms. Acad manag J 55(6):1264-1294 
Judge TA, Thoresen CJ, Bono JE, Patton GK (2001) The job satisfaction-job performance relationship: a qualitative and quantitative review. Psychol Bull $127: 376$

Kasper J (2018) Mind over matter: evaluation of a mindfulness-based stress reduction program for college students. Thesis, Georgia State University

Kiken LG, Garland EL, Bluth K, Palsson OS, Gaylord SA (2015) From a state to a trait: Trajectories of state mindfulness in meditationduring intervention predict changes in trait mindfulness. Pers Individ differ 81:41-46

Knight J (2015) Internationalization: a decade of changes and challenges. International Higher Education 50:6-7

Krueger P, White D, Meaney C, Kwong J, Antao V, Kim F (2017) Predictors of job satisfaction among academic family medicine faculty: findings from a faculty work-life and leadership survey. Can Fam Physician 63:e177-e185

Langer EJ (1998) The power of mindful learning. Perseus Books, Reading

Langer, E. J. (1989) Mindfulness. Addison-Wesley/Addison Wesley Longman

Lebares CC, Guvva EV, Ascher NL, O'Sullivan PS, Harris HW, Epel ES (2018) Burnout and stress among US surgery residents: psychological distress and resilience. J Am College Surg 226:80-90

Lee J, Corbett JM (2006) The impact of downsizing on employees' affective commitment. J Manag Psychol 21:176-199

Li J (2018) Translating idea into reality? A Q-methodological investigation of Chinese local officials' response to the initiative of a happiness index. Social Indicators Research 139:433-452

Locke EA (1969) What is job satisfaction? Organ Behav Hum Perform 4:309-336

Luchak AA (2003) What kind of voice do loyal employees use? Br J Ind Relat 41:115-134

Luo Y, Wang Z, Zhang H, Chen A, Quan S (2016) The effect of perfectionism on school burnout among adolescence: rhe mediator of self-esteem and coping style. Personal Individ Differ 88:202-208

Lynch S et al. (2011) Mindfulness-based coping with university life: a nonrandomized wait-list controlled pilot evaluation. Stress Health 27:365-375

Macky K, Boxall P (2007) The relationship between 'high-performance work practices' and employee attitudes: an investigation of additive and interaction effects. Int J Hum Resource Manag 18:537-567

Malouf ET, Youman K, Stuewig J, Witt EA, Tangney JP (2017) A pilot RCT of a values-based mindfulness group intervention with jail inmates: evidence for reduction in post-release risk behavior. Mindfulness 8:603-614

Martin JR (1997) Mindfulness: a proposed common factor. J Psychother Integr 7:291-312

Maslach C, Jackson SE, Leiter MP (1996) Maslach burnout inventory manual, 3rd edn. Consulting Psychologists Press, Palo Alto

Maslach C, Schaufeli WB, Leiter MP (2001) Job burnout. Annu Rev Psychol $52: 397-422$

Maynes TD, Podsakoff PM (2014) Speaking more broadly: an examination of the nature, antecedents, and consequences of an expanded set of employee voice behaviors. J Appl Psychol 99:87

Medvedev ON, Krägeloh CU, Narayanan A, Siegert RJ (2017) Measuring mindfulness: applying generalizability theory to distinguish between state and trait. Mindfulness 8(4):1036-1046

Messersmith JG, Patel PC, Lepak DP, Gould-Williams JS (2011) Unlocking the black box: exploring the link between high-performance work systems and performance. J Appl Psychol 96:1105

Mesmer-Magnus J, Manapragada A, Viswesvaran C, Allen JW (2017) Trait mindfulness at work: a meta-analysis of the personal and professional correlates of trait mindfulness. Human Perform 30:1-20

Miao R, Cao Y (2019) High-performance work system, work well-being, and employee creativity: cross-level moderating role of transformational leadership. Int J Environ Res Public Health 16:1640

Michel A, Bosch C, Rexroth M (2014) Mindfulness as a cognitive-emotional segmentation strategy: an intervention promoting work-life balance. J Occup Organ Psychol 87:733-754

Montani F, Dagenais-Desmarais V, Giorgi G, Grégoire S (2018) A conservation of resources perspective on negative affect and innovative work behaviour: the role of affect activation and mindfulness. J Bus Psychol 33:123-139

Naeem A, Mirza NH, Ayyub RM, Lodhi RN (2019) HRM practices and faculty's knowledge sharing behavior: mediation of affective commitment and affectbased trust. Stud High Educ 44:499-512

National Institutional Ranking Framework (NIRF) (2018) https://www.nirfindia. org/2018/Ranking2018.html. Accessed 12 Dec 19

Ng TW, Feldman DC (2012) Employee voice behavior: a meta-analytic test of the conservation of resources framework. J Organ Behav 33:216-234

Ng TW, Feldman DC, Butts MM (2014) Psychological contract breaches and employee voice behaviour: the moderating effects of changes in social relationships. Eur J Work Organ Psychol 23:537-553

O’Reilly M (1998) Radical presence: teaching as a contemplative practice. Boynton/ Cook, Portsmouth
Oeij PR, Van Vuuren T, Dhondt S, Gaspersz J, De Vroome EM (2018) Mindful infrastructure as antecedent of innovation resilience behaviour of project teams: learning from HROs. Team Perform Manag 24:435-456

Ostafin BD, Kassman KT (2012) Stepping out of history: mindfulness improves insight problem solving. Conscious Cognit 21:1031-1036

Peterson SJ, Luthans F, Avolio BJ, Walumbwa FO, Zhang Z (2011) Psychological capital and employee performance: a latent growth modeling approach. Pers Psychol 64:427-450

Peterson U, Demerouti E, Bergström G, Samuelsson M, Åsberg M, Nygren A (2008) Burnout and physical and mental health among Swedish healthcare workers. J Adv Nurs 62:84-95

Pines AM (2017) Burnout: an existential perspective. In: W Schaufeli, C Maslach, \& T Marek (Eds), Professional burnout. Routledge, pp. 33-51

Podsakoff PM, MacKenzie SB, Lee JY, Podsakoff NP (2003) Common method biases in behavioral research: a critical review of the literature and recommended remedies. J Appl Psychol 88:879-903

Preacher KJ, Hayes AF (2008) Asymptotic and resampling strategies for assessing and comparing indirect effects in multiple mediator models. Behav Res Methods 40:879-891

Ramler TR, Tennison LR, Lynch J, Murphy P (2016) Mindfulness and the college transition: the efficacy of an adapted mindfulness-based stress reduction intervention in fostering adjustment among first-year students. Mindfulness 7:179-188

Reb J, Narayanan J (2014) The influence of mindful attention on value claiming in distributive negotiations: evidence from four laboratory experiments. Mindfulness 5:756-766

Ritchie TD, Bryant FB (2012) Positive state mindfulness: a multidimensional model of mindfulness in relation to positive experience. Int $\mathrm{J}$ Wellbeing 2 (3):150-181

Saavedra MC, Chapman KE, Rogge RD (2010) Clarifying links between attachment and relationship quality: hostile conflict and mindfulness as moderators. J Fam Psychol 24:380

Salanova M, Peiró JM, Schaufeli WB (2002) Self-efficacy specificity and burnout among information technology workers: an extension of the job demandcontrol model. Eur J Work Organ Psychol 11:1-25

Schwind JK, McCay E, Beanlands H, Martin LS, Martin J, Binder M (2017) Mindfulness practice as a teaching-learning strategy in higher education: a qualitative exploratory pilot study. Nurse Educ Today 50:92-96

Shapiro SL, Carlson LE, Astin JA, Freedman B (2006) Mechanisms of mindfulness. J Clin Psychol 62:373-386

Shepherd DA, Patzelt H, Berry CM (2019) Why didn't you tell me? Voicing concerns over objective information about a project's flaws. J Manag 45:1087-1113

Shih HA, Chiang YH, Hsu CC (2006) Can high performance work systems really lead to better performance? Int J Manpower 27:741-763

Shore LM, Wayne SJ (1993) Commitment and employee behavior: comparison of affective commitment and continuance commitment with perceived organizational support. J Appl Psychol 78:774

Siegel DJ (2007) Mindfulness training and neural integration: Differentiation of distinct streams of awareness and the cultivation of well-being. Soc Cogn Affect Neurosci 2(4):259-263

Sobel ME (1982) Asymptotic confidence intervals for indirect effects in structural equation models. In: Leinhart S (Ed.) Sociological methodology. Jossey-Bass, San Francisco, pp. 290-312

Sternberg RJ (2000) Images of mindfulness. J Soc Issues 56:11-26

Stupnisky RH, BrckaLorenz A, Yuhas B, Guay F (2018) Faculty members' motivation for teaching and best practices: testing a model based on selfdetermination theory across institution types. Contemp Educ Psychol 53:15-26

Swanson EB, Ramiller NC (2004) Innovating mindfully with information technology. MIS Q 553-583

Takeuchi R, Chen G, Lepak DP (2009) Through the looking glass of a social system: cross-level effects of high-performance work systems on employees' attitudes. Pers Psychol 62:1-29

Trivellas P, Santouridis I (2016) Job satisfaction as a mediator of the relationship between service quality and organisational commitment in higher education. An empirical study of faculty and administration staff. Total Qual Manag Bus Excell 27:169-183

Tuckey MR, Sonnentag S, Bryan J (2018) Are state mindfulness and state work engagement related during the workday? Work Stress 32:33-48

Ucok O (2006) Transparency, communication and mindfulness. J Manag Dev 25:1024-1028

Valentine S, Godkin L, Varca PE (2010) Role conflict, mindfulness, and organizational ethics in an education-based healthcare institution. J Bus Eth 94:455-469

Vandenberghe C, Bentein K, Panaccio A (2017) Affective commitment to organizations and supervisors and turnover: a role theory perspective. J Manag 43:2090-2117 
Victorino C, Nylund-Gibson K, Conley S (2018) Prosocial behavior in the professoriate: a multi-level analysis of pretenured faculty collegiality and job satisfaction. Int J Educ Manag 32:783-798

Vogus TJ, Sutcliffe KM (2012) Organizational mindfulness and mindful organizing: a reconciliation and path forward. Acad Manag Learn Educ 11:722-735

Wielgosz J, Goldberg SB, Kral TR, Dunne JD, Davidson RJ (2018) Mindfulness meditation and psychopathology. Annu Rev Clin Psychol 15:285-316

Wilski M, Chmielewski B, Tomczak M (2015) Work locus of control and burnout in Polish physiotherapists: the mediating effect of coping styles. Int J Occup Med Environ Health 28:875

Womack JP, Womack JP, Jones DT, Roos D (1990) Machine that changed the world. Free Press, Simon and Schuster; Inc, New York

Wu PC, Chaturvedi S (2009) The role of procedural justice and power distance in the relationship between high performance work systems and employee attitudes: a multilevel perspective. J Manag 35:1228-1247

Zivnuska S, Kacmar KM, Ferguson M, Carlson DS (2016) Mindfulness at work: resource accumulation, well-being, and attitudes. Career Dev Int 21 (2):106-124

\section{Competing interests}

The author declares no competing interests.

\section{Additional information}

Correspondence and requests for materials should be addressed to S.J.

Reprints and permission information is available at http://www.nature.com/reprints

Publisher's note Springer Nature remains neutral with regard to jurisdictional claims in published maps and institutional affiliations.

\begin{abstract}
(c) (i) Open Access This article is licensed under a Creative Commons Attribution 4.0 International License, which permits use, sharing, adaptation, distribution and reproduction in any medium or format, as long as you give appropriate credit to the original author(s) and the source, provide a link to the Creative Commons license, and indicate if changes were made. The images or other third party material in this article are included in the article's Creative Commons license, unless indicated otherwise in a credit line to the material. If material is not included in the article's Creative Commons license and your intended use is not permitted by statutory regulation or exceeds the permitted use, you will need to obtain permission directly from the copyright holder. To view a copy of this license, visit http://creativecommons.org/ licenses/by/4.0/.
\end{abstract}

(C) The Author(s) 2021 